\title{
Article
}

\section{From the Lesson Tee to the Course: A Naturalistic Investigation of Attentional Focus in Elite Golf}

Orr, Steven, Cruickshank, Andrew and Carson, Howie J.

Available at http://clok.uclan.ac.uk/40151/

Orr, Steven, Cruickshank, Andrew ORCID: 0000-0002-8893-2341 and Carson, Howie J. (2021) From the Lesson Tee to the Course: A Naturalistic Investigation of Attentional Focus in Elite Golf. The Sport Psychologist, 35 (4). pp. 305-319. ISSN 0888-4781

It is advisable to refer to the publisher's version if you intend to cite from the work. http://dx.doi.org/10.1123/tsp.2021-0003

For more information about UCLan's research in this area go to http://www.uclan.ac.uk/researchgroups/ and search for <name of research Group>.

For information about Research generally at UCLan please go to http://www.uclan.ac.uk/research/

All outputs in CLoK are protected by Intellectual Property Rights law, including Copyright law. Copyright, IPR and Moral Rights for the works on this site are retained by the individual authors and/or other copyright owners. Terms and conditions for use of this material are defined in the policies page.

\section{CLoK}

Central Lancashire online Knowledge www.clok.uclan.ac.uk

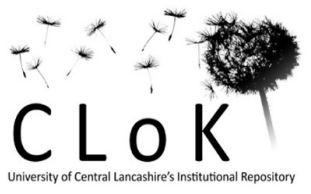




\title{
THE UNIVERSITY of EDINBURGH
}

\author{
Edinburgh Research Explorer
}

\section{From the lesson tee to the course}

\section{Citation for published version:}

Orr, S, Cruickshank, A \& Carson, HJ 2021, 'From the lesson tee to the course: A naturalistic investigation of attentional focus in elite golf', The Sport Psychologist, vol. 35, no. 4, pp. 305-319.

https://doi.org/10.1123/tsp.2021-0003

\section{Digital Object Identifier (DOI):}

10.1123/tsp.2021-0003

Link:

Link to publication record in Edinburgh Research Explorer

Document Version:

Peer reviewed version

Published In:

The Sport Psychologist

Publisher Rights Statement:

Accepted author manuscript version reprinted, by permission, from Sport Psychologist, 2021, https://doi.org/10.1123/tsp.2021-0003. (C) Human Kinetics, Inc.

\section{General rights}

Copyright for the publications made accessible via the Edinburgh Research Explorer is retained by the author(s) and / or other copyright owners and it is a condition of accessing these publications that users recognise and abide by the legal requirements associated with these rights.

\section{Take down policy}

The University of Edinburgh has made every reasonable effort to ensure that Edinburgh Research Explorer content complies with UK legislation. If you believe that the public display of this file breaches copyright please contact openaccess@ed.ac.uk providing details, and we will remove access to the work immediately and investigate your claim. 
From the Lesson Tee to the Course: A Naturalistic Investigation of Attentional Focus in Elite Golf

Steven Orr $^{1 *}$, Andrew Cruickshank ${ }^{1,2}$ and Howie J. Carson ${ }^{3}$

${ }^{1}$ Institute for Coaching and Performance, University of Central Lancashire

${ }^{2}$ Grey Matters Performance Ltd., UK

${ }^{3}$ Institute for Sport, Physical Education and Health Sciences, Moray House School of Education and Sport, The University of Edinburgh

*Correspondence concerning the article should be addressed to Steven Orr, Rustington Golf Centre, Golfers Lane, Angmering, West Sussex, BN16 4NB

Email: steven@stevenorrcoaching.com 


\section{Abstract}

2 While debate continues on "optimal" attentional focus, little empirical knowledge exists on

3 the way that attention is operationalized across training and performance in elite golf.

4 Accordingly, this study aimed to: (a) explore the attentional foci promoted or used by

5 coaches and players for different types of shots in training, plus their underpinning rationale;

6 and (b) explore the attentional foci promoted or used by coaches and players in competition,

7 plus their underpinning rationale. Our findings revealed that: (a) various foci were used

8 across training and competition; (b) all players used different combinations of foci across

9 training and competition, and within different aspects of training itself (e.g., short vs. long

10 game); and (c) players often used alternative or additional foci in training to those promoted

11 by coaches, and self-generated foci for competition. These results highlight the complexity and practical reality that needs to underpin future advances in theory, research, and practice. 
From the Lesson Tee to the Course: A Naturalistic Investigation of Attentional Focus in Elite Golf

In the applied domain of golf, as in most self-paced sports, technique plays an important role. Coaching knowledge and empirical evidence tell us that a range of complex factors influence technical development for use during competition; including a player's attentional focus (Wulf \& Su, 2007). Indeed, much prior work has asserted that what a player focuses on before, during, and after an execution significantly influences technical form and outcome success (e.g., for tasks such as driving or chipping the golf ball; Singer, 1986).

Beyond this general headline, however, academic debate regarding an "optimal" attentional focus continues. Yet, at present, little empirical knowledge exists on the approaches promoted by those who, by and large, influence players the most: coaches. Clearly, this is a significant problem if the attentional focus process in golf is to be considered a sufficiently "well-functioning" applied science (cf. Giacobbi Jr. et al., 2005). As such, this study aimed to explore what, when, how, and, most significantly, why, coaches and players use attentional focus strategies. Ultimately, it was hoped that this study would offer a chance to compare and contrast current literature with actual coaching knowledge and practice.

\section{Contextualizing Applied Sport Research: Its Beginnings and Where Are We Now?}

To contextualize the necessity of our approach, Christina (1987) commented on and critiqued motor learning and control research. He described how "stimulus-response" investigations had previously (1950s and 1960s) focused on solving applied questions with the aim of improving performance within skill-based professions (e.g., sports and aviation). Following adoption of the "information-processing" approach (1970s and 1980s) however, research focused on the cognitive mechanisms acting on stimuli to elicit responses, with little regard for the type of outcome and how that might translate to real-world performance. While prioritizing theoretical development, applied research was viewed as subordinate and 
dependant on basic/fundamental understanding, thus offering little insight or value in its own right. Consequently, studies mainly involved novices executing simple laboratory tasks.

Christina's concern was that we knew little about the cognitive processes of highly practiced and/or skilled performances, and that this mattered because:

we cannot be certain that the cognitive processes involved in learning and performing simple motor responses (a) are the same, (b) operate in the same way, and (c) are affected by the same variables in the same way as those found in learning and performing complex motor responses. (p. 33)

Perhaps controversial, was the idea that applied research could inform basic/fundamental theory. Thus, by the late 1980s the field was at a critical juncture in its development on where to turn for a deeper understanding.

More recently (1990s and 2000s), the inclusion of skilled athletes (although rarely true “elites”) has been increasingly prevalent within research, however Christina’s (1987) concerns, amongst other emergent issues, have remained for some applied researchers (e.g., Bobrownicki et al., 2018; D. Collins et al., 2016; Toner \& Moran, 2015). Specifically, many concerns relate to investigations into the influence of attentional focus during motor learning, performance, and refinement (e.g., Beilock et al., 2002; Gray, 2018; Masters \& Maxwell, 2008; Wulf, 2013). In terms of these investigations, most fundamental research studies have reported benefits of reduced or no conscious attention towards movement mechanics compared to directing conscious attention towards movement mechanics (see Masters \& Maxwell, 2008; Wulf, 2013). One prominent idea is the "constrained action hypothesis" which concerns the use of an external or internal focus during learning and performance. Within this literature, an external focus is defined as thoughts that "direct the performer's attention away from his or her body movements and to the effects that those movements have on the environment" and an internal focus is defined as thoughts "referring to the performer's 
body movement" (Wulf et al., 1998, p. 170). Other related frameworks have also been proposed; "reinvestment" (Masters \& Maxwell, 2008) and the "explicit monitoring hypothesis" (Beilock \& Carr, 2001). Both specifically relate to the phenomenon of "choking" under pressure. The former has been derived from studies of novice performers and suggests that for individuals with a high propensity to think excessively using rule-based knowledge, this tends to underpin a deterioration of performance. The latter hypothesis on the other hand, tested with novices and skilled performers, explains that monitoring of the movement mechanics in a step-by-step manner is only detrimental to skilled performers. While subtly different in their mechanistic underpinnings, all these bodies of literature offer strategies to avoid attention towards the movement (e.g., external focus, implicit motor learning, or dualtask conditions) as a means to prevent negative deautomation effects. Importantly for our applied focus, findings from these experiments have led Wulf(2016) to describe an external focus as a "condition sine qua non for athletes" (p. 1293) and that "continuing to rely on "practitioner wisdom" [i.e., internal focus instructions/foci] and ignoring strong evidence for the advantages of an external attentional focus provides a disservice to athletes" (p. 1294). So, for some at least, the matter is closed: an external focus is best for any athlete, in any circumstance, and for any purpose.

\section{Contradictions with Applied Research Studies: Realizing Contextual Differences}

Contrary to these fundamental research findings, however, applied research suggests a more facilitative role for internal foci within training and performance settings. For example, Carson and Collins (2011) proposed that a narrow internal focus is necessary when initiating small technical refinements to already well-established and automated skills (e.g., Hanin et al., 2002). Early on during refinement, becoming aware of the erroneous movement is necessary to lower the risk of future regression. In golf, this might mean focussing on the feel of leading with the hip at the start of the downswing or turning the chest to increase the 
length of swing. Once the change has been both realized and later (re)automated, using an external focus of attention will be required (at least in part) within more naturalistic training and performance environments, to correctly identify relevant information for the task.

Interestingly, the only study to employ implicit methods (so avoiding an internal focus) for technical refinement with elite athletes resulted in the opposite kinematic change intended and poorer performance (see Rendell et al., 2011). Toner and Moran (2015) also explained that performers should deliberately prevent overly automating skills to ensure adaptability in novel environments and/or physical performance requirements. In golf, this might include temporarily adapting technique to an awkward lie in a hazard, or simply when attempting to shape shots. Here, it is important that the golfer has a clear understanding of cause-effect between the ball flight characteristics and movement pattern; a process developed within the associative learning stage (Fitts \& Posner, 1967). Evidently, contrasting simple tasks used within fundamental research studies with more varied real-world contexts provides a different, more dynamic perspective on the role of attentional focus and its utilization. Notably, while Wulf (2016) is fixed on the view that an external focus is absolute, Poolton and Zachry (2007) accept that implicit motor learning is not always appropriate or feasible within real-world settings. It is, therefore, necessary to further test and develop our ideas in this area.

\section{Naturalistic Applied Research in Sport: A Dynamic and Complex Picture}

Empirically, research has also investigated attentional focus use within naturalistic settings and across a range of different sports. Within judo, Bahmani et al. (2019) explored the attentional strategies of experts following competitive bouts using simulated recall.

"Technique" constituted the most frequent focus, sometimes in a narrow direction (e.g., focussing on leg position) and sometimes holistically (e.g., exploding, being fast). Overall conclusions were that attentional foci were complex, dynamic, and multidirectional, 
integrating psychological states, strategies and tactics, situational awareness, and extraneous sources. Within boxing, Halperin et al. (2016) explored the verbal feedback statements of coaches between competition rounds. Feedback before successful rounds was generally (but not exclusively) external, less controlling, and more positive in nature; the opposite was true for unsuccessful rounds. Despite a lack of manipulation checks, this study benefits from the rare addition of performance outcome information.

Turning towards closed and self-paced sports, within elite field athletics, athletes report using internal foci to regulate their actions, by focusing on the action's entirety through its rhythmic temporal (i.e., timing) and/or kinaesthetic (i.e., feel) characteristics (e.g., MacPherson et al., 2008). In pistol shooting, a coping strategy has also been reported in the form of consciously stabilizing important but insufficiently automated action components (Bortoli et al., 2012). Finally, in a survey by Porter et al. (2010), 85\% of national track and field athletes reported that coaches provided internal focussing instructions, but only $69 \%$ reported using these in competition. So, reflecting diverse applied contexts, research shows that attentional strategies differ and are not always congruent with what is being coached. Within the golf coaching/performance context, relatively few studies have been conducted within naturalistic settings (cf. Christina, 1987). Bernier et al. (2011) characterized experts in training and competition. In training, golfers were filmed and interviewed on one specific skill (e.g., putting), whereas in competition, golfers were filmed and interviewed regarding the first three holes. In training, focus was mainly on "process" with visual and kinaesthetic senses, whereas a competition focus was mainly on results with a visual sense. In short, attentional foci of expert golfers appeared more diverse and more nuanced than simply internal/external foci, for instance. Reflecting this diverse application of foci, following observations of practice sessions, semi-structured interviews, and focus groups, participants reported a dynamic focus of attention between internal and external depending on the type of 
golf shot and demands; what Diekfuss and Raisbeck (2017) termed a "situational focus", with an internal focus reported more for long drives and short putts. In support, Diekfuss and Raisbeck (2016) found no Division 1 golfer to report using only an external focus of attention in their survey. More recently, Oliver et al. (2020) employed a think-aloud protocol with seven club golfers $\left(M_{\text {handicap }}=14\right)$ on six different holes of their own golf course. Data revealed a range of attentional strategies, notably categorized as both internal and external. Specifically, golfers focussed on a visual point of reference when lining up their shot (e.g., a tree in the distance) followed by an internal focus towards a specific technical instruction (e.g., shoulder turn; see Loze et al., 2001). Therefore, consistent with research outside of golf, and in contrast to the fundamental research described earlier, applied researchers have found that performers both use - and perceive benefits of — different foci in various contexts and with different aims. Accordingly, we suggest that an understanding of attentional focus within performance domains, including elite golf, is incomplete and warrants further investigation into its operationalization from a playing and coaching perspective.

To reconcile this discrepancy between fundamental and applied research, it is useful to note several methodological oversights. Firstly, an imbalance of instructional information between conditions in fundamental research studies has presented questionable comparison groups, raised issues with working memory capacity, conflicted with current coaching practice (e.g., Schempp et al., 2004), and thus has limited relevance and generalizability (Bobrownicki et al., 2018). Secondly, the extent to which a performer might be impacted by their level of familiarity with a particular technical focus as part of their normal routine and the usefulness of such a focus relative to the executional demands (e.g., an explosive whole body movement will not be facilitated by a focus solely on a finger's movement, whereas the feeling of proximal-distal acceleration driven by core body muscles would be; Carson et al., 2013), are often underconsidered (D. Collins et al., 2016). Thirdly, tasks have been overly 
simplistic and failed to represent dynamic real-world performance conditions (Christensen et al., 2016). Therefore, while it is plausible that an externally (or internally) focused, fully (and not fully) automated execution might bring benefit for some performers executing some skills in some contexts, there needs to be further study to explore the process in an applied context if research aspires to have the greatest impact on real-life practice and performance.

\section{"Applied Theory" to Reflect Applied Challenges}

Having identified these limitations, several noteworthy attempts have already been made to advance theory in a way that explains inconsistencies in attentional focus literature. Reflecting Christina's (1987) recommendation not to isolate cognitive and motor response processes, there has been a growing interest in interdisciplinary research, to understand realworld challenges and to drive an innovative applied service; a recognized need to go "back to the future" (Collins \& Carson, 2017, p. 13). Indeed, recent proposals of a motoric dimension to interpret attentional processes during anxiety-impacted performances (see Carson \& Collins, 2016), the multi-action plan (see Bortoli et al., 2012), and the theory of meshed control (see Christensen et al., 2016) all provide multi-factorial and contextually-dependent accounts of how different attentional foci can influence skill outcomes. In short, the suggested answer to whether an internal/external focus of attention, or implicit/explicit learning works best, is "it depends" (i.e., not ruling out the possibility of a single strategy or multiple strategies depending on the desired outcome, performer needs, and contextual factors). Notably, these approaches explain experts as proficient in switching between internal/external/skill/dual-task foci in response to the interactions between performer (e.g., their technical needs, physical state and/or level of arousal), environmental (e.g., importance and type of context/situation), and task (e.g., simple-complex) demands; so, in contrast to many fundamental research studies that emphasize efficiency as a criterion for successful performance (i.e., low/no conscious processing and high performance success; Beilock \& 
Carr, 2001; Masters \& Maxwell, 2008). Successful and elite-level performance is characterized by different levels of pressure within a performance and therefore requiring different types of attentional states.

Accordingly, research in elite golf would benefit by taking an even closer look at performance issues, beyond group comparisons, and, ideally, consider more complete and ecologically valid skill sets; for instance, consideration beyond the first three holes of a competition and only for one type of skill under training conditions, as reported by Bernier et al. (2011). Additionally, research should include the perspective of both players and coaches. Indeed, while much research has been conducted on attentional focus effects (e.g., Bell \& Hardy, 2009; Wulf \& Su, 2007), there is little empirical evidence to examine how attentional focus is operationalized in the coaching process; particularly with elite performers (Carson et al., 2013). Since effective coaching is dependent on sound judgment and decision making (L. Collins et al., 2016), there is a need to explore what, when, how, and, most significantly, why coaches and players use attentional focus strategies in the real world. Therefore, the objectives of this study were to: (a) explore the attentional foci promoted or used by elitelevel coaches and players when executing different types (i.e., long- and short-game) of golf shots in practice, as well as the rationale for this; and (b) explore the attentional foci promoted or used by elite-level coaches and players in competition, as well as the rationale for this. It was anticipated that the findings would illuminate the actual practices of elite-level golf coaches and players plus, to facilitate the potential for future progress, why coaches and players operate in this way.

\section{Methodology}

\section{Research Philosophy and Design}

Informing both the rationale and purposes outlined in our Introduction, this study was driven by a pragmatic research philosophy. Pragmatism is focused on building solutions to 
specific practical challenges (Denzin \& Lincoln, 2005; Giacobbi Jr. et al., 2005) and, while other paradigms prioritize ontological and epistemological matters, pragmatism has, as its' central focus, research questions and appropriate ways to answer them. Reflecting this, a qualitative strategy was used to explore our aims. Qualitative research has its roots in phenomenology and social action (Jupp, 2006) and suits work that aims to understand what people perceive, believe, and do in the world in which they operate (Strean, 1998). More specifically, and consistent with an ongoing shift from examining focus of attention in laboratories to naturalistic settings (Diekfuss \& Raisbeck, 2016), it was decided that a directly observed coaching session and follow-up, semi-structured interviews with coachplayer pairs would shed some useful light. As such, data collection was approached from the interpretivist side of the epistemological continuum (Chowdhury, 2014); designed to gather rich data on the subjective experiences, practices, and rationale of those involved; or, more specifically, what type of foci they promoted or used and why (Elster, 2007; Whitley, 1984). It was also approached with an awareness of the pragmatics of the research process, in that high-level participants would be more inclined to take part in a single observation plus interview than any longer-term commitment at this stage (Goldkuhl, 2012).

\section{Participants}

Data were collected from 10 coach-player pairs $(N=20)$. Each coach was purposively selected through the personal contacts of the corresponding author and had to have significant experience of working with high-level or aspiring high-level players. Specifically, coaches had to be PGA qualified and working, at a minimum, across county or regional level in the UK (where the research team had best access to coaches and players). Furthermore, each coach had to have a track record of developing national level amateurs and/or tournament professionals. Subsequently, all coaches were either regional or national coaches (or coaching players in these squads), with the majority of coaches $(N=6)$ also 
coaching players on the professional European Tour, Challenge Tour, or Europro Tour.

Overall, coaches were all male, aged between $31-54$ years $(M=40.2 ; S D=6.38)$, and had coached for $11-30$ years $(M=18.1 ; S D=5.87)$.

Player recruitment was supported by the coaches, with each coach asked to identify an appropriately high-level, competitive player with whom they coached and had an established relationship with (> 1 year). In terms of selection criteria, any junior players (i.e., those under 18 years old) were required to have a maximum handicap of 3, which mirrored regional-level standards set by UK governing bodies (e.g., this equated to the best 80 juniors in England). For senior players (i.e., those over 18 years old), these individuals were required to have a handicap of 0 or better if an amateur, or to be on one of the aforementioned professional tours. Overall, the player group consisted of 10 males, aged between 16-32 years old ( $M=$ 22.4; $S D=4.79$ ). Six were elite junior or senior amateurs, with the other four professionals who had played at this level for between $2-7$ years $(M=3.9 ; S D=1.91)$. Regarding the latter, one player was currently on the European Challenge Tour and the other three were on either the PGA Europro Tour or Alps Tour. All six amateurs had represented their country with full international honours and won national titles.

\section{Procedure}

All procedures were approved by the lead author's institutional ethics committee. As the first step, conversations were held with a selection of coaches known to meet the selection criteria, with players subsequently invited to participate on the suggestion of the coach. All participants were provided with information sheets and signed consent forms before taking part. Once all had agreed to take part (after considering the study information separately), lesson observations and interviews were arranged at each coach's workplace and at a time convenient to each coach-player pair. 
All data collection procedures were undertaken by the lead researcher. The first phase involved observing the coaching lesson. All sessions took place in the off-season between

December-March, due to it being the easiest time of the year to get a coach and player together, since the golf season from April-September is highly congested. All observed sessions also centred on the long-game rather putting or short game, for instance. This approach was taken to acquire a sufficiently detailed data set from the observation element, as technical training is most common in long-game and therefore where many technical discussions between coach and player tend to take place. It also enabled consistency across the data collected (i.e., the same type of session was observed rather than lots of different types of sessions to help us to draw out some general patterns across coach-player pairs). We should also stress that the observed long-game session provided us with partand not all —of our data set. To clarify, our remaining data were collected via the subsequent interviews; which also elicited information on the focus adopted in short-game practice and competition (as detailed below). To support recall during the interviews, the coaching sessions were filmed on camera (iPad Pro, Apple) and recorded on a Dictaphone. Recordings also supported the accuracy of the ultimate analysis (by coding data against a live account of the session). In practice, this resulted in the researcher and participant engaging with the recordings during the interview process to identify important points of reference and to fully comprehend the context being discussed.

Based on the study objectives, all interviews (also recorded on Dictaphones) were supported by a guide that explored: (a) the focus used by the coach to achieve the session goal as well as their rationale for this; (b) the consistency of the coaches' actions with their goal in the session; (c) how the coach would change the focus for equivalent sessions on short-game shots, if at all, as well as their rationale for this; and (d) how the coach would help the player transition to a competition from an attentional focus perspective. Prompts and 
probes were used to further explore areas of interest. Finally, an equivalent interview was conducted with the player (with all questions exploring what focus the player adopted, or would adopt, and why). Importantly, all interviews with players were conducted separately from the coach to limit the potential influence of power, bias, and impression management in responses (e.g., players feeling they had to agree with their coach; and vice-versa).

Preceding all of the above, a pilot study was conducted involving two coach-player pairs, which helped to shape the clarity and coherence of the interview guides in particular. For example, the need to prepare a breadth of probing and specific questions to understand the coaches' rationale became clear (i.e., decisions on what to do in a session came from multiple sources, such peer influence, experience, education, and norms in golf).

\section{Data Analysis}

All interviews were transcribed and read several times by the lead author to increase familiarity and understanding of the participants' accounts. A similar process was also undertaken with the video data. Primarily led by the first author and supported by the second and third authors (see Trustworthiness section below), data from the videos and interviews were then coded deductively using the headings listed in Table 1 (long-game) and Table 2 (short-game and competition). For clarity, all data on long-game shots were coded according to whether they referred to: (a) the nature of the foci intended to achieve the session goal; (b) the rationale for using these foci; and (c) the match between these intended foci and the actual foci deployed in the session. Secondly, all data on short-game shots were coded according to whether they referred to: (a) the nature of the foci intended to achieve an equivalent goal in short-game practice; and (b) the rationale for these foci. Finally, all data on competition were coded according to whether they referred to: (a) the nature of the foci intended; and (b) the rationale for these foci. Following this, a separate inductive analysis was undertaken to generate labels that summarized the actions or perceptions of the coach or player in each 
aspect. This process followed the steps outlined by Côté et al. (1993), whereby conceptually similar data were progressively grouped to capture the participants' overall perceptions and actions. Similar to the deductive element, and consistent with our pragmatic philosophy (Giacobbi Jr. et al., 2005), the inductive analysis also reflected an iterative and collaborative process, during which all three authors engaged in regular discussion and debate on the most appropriate coding until agreement was reached across the full team.

\section{Addressing Trustworthiness}

Reflecting our pragmatic philosophy, we considered ourselves to be co-constructors of knowledge within this study; building knowledge, filtered through our own experiences, from the participants' interpretations of their own reality (Orlikowski \& Baroudi, 1991). In this regard, a key principle of the pragmatic philosophy is that the applied experiences of researchers can facilitate novel and innovative insights. In short, an understanding of the realities of practice can help to generate practically meaningful knowledge (Bryant, 2009). In this vein, our aim to generate practically meaningful insight was enhanced by our prior and ongoing roles in coaching, educating, and supporting elite golfers and coaches (i.e., the first and third authors are PGA qualified golf coaches and the second author a Chartered Sport \& Exercise Psychologist who supports elite golf coaches and players; Giacobbi Jr. et al., 2005). Of course, however, our experiences and biases had to be appropriately managed to enhance the accuracy and fairness of our interpretations; covering both the data collection and data analysis procedures.

In terms of data collection, the decision to recruit coaches known to the lead author was taken with respect to the pragmatics of the research but also due to the advantage of preexisting rapport (a key factor in shaping the quality of outcomes from interviews; Sparkes \& Smith, 2009). Significantly, this rapport with the coaches - as well as the lead researcher's experience of coaching at the elite level—also supported rapport with the players (through an 
understanding of the nature and challenges of high-level golf, and the specific areas that were being worked on with their coach). Efforts to optimize rapport were also made by gaining an understanding of each player's history and progress in the previous season. As evidence for the levels of rapport, several discussions continued on contemporary playing and coaching issues after the interviews had terminated. Additionally, six coaches subsequently contacted the first author to ask for feedback on the overall results from the study.

Regarding data analysis, member reflections were acquired to support accuracy, fairness, and balance in the findings presented. Specifically, participants were asked to review their data and highlight gaps or offer further insight as desired (Smith \& McGannon, 2018). Brief reflections were provided by five coaches and three players, with no major changes made to the original text. Beyond member reflections, the second and third authors acted as critical friends throughout the analysis, helping the lead researcher to reflect on their assumptions and biases (and vice-versa); for example, by challenging the first author's interpretations in the deductive element and suggesting alternative coding in the inductive element (Faulkner \& Sparkes, 1999; Smith, 2018). As part of this, the lead author repeatedly shared versions of the developing results to enhance transparency in the analysis, with a reflexive diary and conversation log kept across all authors to provide a trail of the rationale behind the various evolutions in the findings and the perspectives of the research team (Smith \& McGannon, 2018). Regarding the latter-and to support further reflexivity in our account (Culver et al., 2012) - the first author approached this study with a preference to use an external focus of attention in all circumstances - these thoughts are well known and documented within the golf coaching industry. However, through the data collection and analysis process, this position has been unsettled by a deeper consideration of the demands on players at this high level, consequently opening up to the possibility of a need for a more nuanced and less dichotomous perspective. 


\section{Results}

The results of this study are presented in two parts. First, an overview on the actions and perceptions of the coaches and players, as developed through the deductive analysis procedure, are presented in Table 1 and Table 2. A narrative structured against these tables and the purposes of the paper, drawing on direct quotes from participants, is then presented below. For each of the study's purposes, consideration is given to the attentional foci used and the rationale for this from both the coaches' and players' perspective. Percentages are provided for each findings, however these are simply to express the commonality of a response and should not be interpreted as an indicator of their significance.

$$
\text { ***Table } 1 \text { and Table } 2 \text { Here*** }
$$

\section{Long-Game Training: Attentional Foci Used and Their Rationale}

As evident in Table 1, coaches used numerous cues when working on long-game shots, covering body components/position, club components/position, outcome of the skill, and feeling, rhythm, and timing. In this respect, six coaches $(60 \%)$ used a combination of cues within the session rather than one cue explicitly (see Coaches 1, 3, 4, 5, 7, 9 in Table 1). However, coaches had a clear preference for certain cues. More specifically, in all but one session, coaches $(90 \%)$ used body components/position to explain the desired technique. Moreover, four coaches (40\%) focused exclusively on these cues. For example, in some cases these cues were used for postural changes at address, such as "set up and balance" (Coach 3) and "weight more on left side at address" (Coach 4). They were also used for dynamic movements, such as "connection" (of upper arm to body: Coach 3) and "pressure in the right foot longer" (Coach 9). 
Notably, personal experience as a coach and/or player was reported as the rationale

388

389

390

391

392

393

394

395

396

397

398

399

400

401

402

403

404

405

406

407

408

409

410

411 for cue selection among eight coaches (80\%). For example, one coach said that performing well was a rationale for coaching his player in the same way:

I've tried to get ... my players to focus externally. This extends to what I did. When I played really well, I thought about what I needed the golf club to do.... I always try to get [Player 3] to stay external and remind him the game is played out there.

Additionally, knowledge of the player was also highlighted as a key factor in deciding which cues to promote on the part of the coaches: "Every player is different" (Coach 6); "[The goal is to] reacquaint him with the things he was doing when he was playing well" (Coach 6). In this vein, this coach acknowledged that his exclusive promotion of body components/position was grounded in what had seemed to help the player in the past: "[Player 6] is more internal rather than external. He is better with internal cues. This could be because of how he has been coached [by me] since he was 11 years old". Two coaches (20\%) also referred to nonspecific research to inform their rationale. Coach 5 expressed his preference for using external cues because he felt: "The more you focus on the micromovements, the internal movements, it becomes too difficult. It doesn't work". Coach 9 expressed: "Research suggests that external cues may be more effective”. However, Coach 9 did not explicitly state in what way they were more effective, nor the research source.

From a player's perspective, the attentional cues employed reflected those promoted by their coach (Table 1). As such, the nature of the chosen focus was predominantly $(80 \%)$ body components/position, for both address posture and dynamic movements. Of the few exceptions to this (20\%), Player 9 discussed "[club]face stability on the way back, less flippy on the way through". Another player identified "missing the alignment stick on the followthrough", which was a task the coach had set him to promote the correct downswing club path. However, as previously noted, a focus on club components, the outcome of the skill, 
and feeling, rhythm, and timing were limited and greatly outweighed by body component cues.

Moving from what they did to why they did it, the rationale that all players reported for their chosen focus was to follow the coach's directions. Indeed, the coach seemed to be an influential agent in this process. Additionally, from observations and analyses of the sessions, it was clear that the coach was consistent with what they said and did (see column 5 in Table 1). In contrast, however, and despite stating that their focus was driven by the coach, golfers were inconsistent with applying what the coach had recommended. For example, despite being consistent in the type of focus (body components) only two players were highly consistent in terms of the specific attentional foci promoted by the coach and the attentional foci adopted by the golfer. Specifically, many of the golfers $(80 \%)$ would use cues beyond those that the coach was asking them to use. For example, Coach 1 asked their golfer to focus on club components and general set up positions (body components); however, the player reported focusing on their 'left shoulder, left foot, hands facing downwards, and trunk rotation' as well, which was not mentioned by the coach in the session. As another example, Coach 7 asked his player to focus on club components (awareness on strike location) and the outcome of the skill (ball flight); however, Player 7 reported an entirely different type of focus and content (transition of the club/legs more stable/flatten left wrist). Therefore, in this example, it was clear that the focus promoted by the coach and focus applied by the player was notably different (i.e., the coach asked the player to focus on club components, but the player focused on body components exclusively). This inconsistency was further highlighted when, despite the coach stating that "positional instruction doesn't fit in with him", the golfer stated areas to work on as "left foot flared, hands face down, arm length on backswing". 
When discussing short shots around the green, coaches emphasized a notably different

437 focus compared to coaching long-game shots (Table 2). While body components/positions

438

439

440

441

442

443

444

445

446

447

448

449

450

451

452

453

454

455

456

457

458

459

460 were the main type of cue utilized in long-game, nine coaches $(90 \%)$ used either skill

outcomes, club components, or a combination of both in short-game practice, with only one coach (10\%) using body components exclusively. Regarding skill outcomes, coaches encouraged a focus on aspects such as the ball's flight, landing spot, and finish position. Regarding club components, they also emphasized club mechanics; such as how the club releases, the up and down movements of the club, the clubface angle, and how the club strikes the ball.

In an attempt to rationalize this change in focus from long-game shots, eight coaches (80\%) discussed short-game shots as being smaller, simpler, more skill based, and more varied. For example, Coach 6 suggested that there is "less impact on the body" and so less need to focus on this compared to full shots. Coach 1, who promoted focus on club components or position, also noted the greater variability in short-game and the need to come up with more solutions: "there is more freedom and wider boundaries in short game. No two shots are the same".

Moving from coaches to the golfers, the preferred type of focus largely changed from primarily body components/positions to club components, outcome of the skill, and feeling, rhythm, timing, with only one player focusing exclusively on body components. When describing the outcome of the skill, seven golfers (70\%) specifically described either the shot itself, the landing spot of the ball, or where they wanted the ball to finish as being important. When describing club components, four golfers (40\%) described changing elements of the club, such as the loft on the face or shaft angle at impact to produce the desired ball flight. When describing feeling, rhythm, and timing, players discussed a reduced mental load, and the need to be able to sense and feel the required shot. 
In terms of the players' explanations, this change of focus in short compared to long

462

463

464 game was typically related to less need for technical information and also that these types of shots were more "feel based". Player 1 rationalized this need for less information as: "These shots are $90 \%$ feel...I don't need as much detail here as full shots”. Player 3 explained this difference from the perspective of the importance of feel: "These shots are massively different. For me, short game is all about feel and visualization. I practice with four [different] irons...it's feelings and reactions...less systematic, more reaction.”

\section{Competition: Attentional Foci Used and Their Rationale}

In contrast to the input on long-game practice, coaches seemed to play a minimal role during competition, with players largely deciding what to focus on. Indeed, all players $(100 \%)$ reported "experience" as the main determinant of their focus, with a minority $(20 \%)$ incorporating coaching advice into their focus for events. From the coach's perspective, directions became broader, such as advice to focus "on the process rather than the outcome" and "focusing on what the player can control 100\%". Also, a common desire by coaches was for the player to "have no swing thoughts". Coach 10 explained the transition between training and competition foci as requiring the player to "park the technical bit". Some coaches $(40 \%)$ were explicit about not transferring foci from training into competition, acknowledging that these cues may not be effective; although this view was not universal, as Coach 1 explained: 'Because [player] doesn't practice much it's important to be able to give him something he can take onto the golf course and play with".

Ultimately, it was clear that all coaches (100\%) passed responsibility of cue selection to the player as they transitioned from the lesson tee to competition. That is, none of the coaches were directly responsible for informing a player's attentional strategy for competing, nor did they train specific cues to achieve the desired outcomes mentioned. Coach 3 said: 
I would give the reigns to him. I would ask him questions so that I can understand firstly what he is putting his focus on. Get him to qualify it. If it set an alarm bell off, I might question it...I think with good players a lot of it has to be their ideas.

Similarly, Coach 4 added: "We agree what that [focus] is but he would come up with it and then run it past me". Coach 6 also highlighted: "I wouldn't bring that [i.e., focus for competition] up. I would let the player bring that up. I haven't advised him what to focus on. I've never advised him against or for a certain thought". Finally, Coach 9 spoke of the player telling him about choice of focus "after he played. He could use me as a sounding board. What he thinks about comes more from him".

This stark contrast in the coaches' role and influence on players' foci (i.e., high in training but low in competition) was corroborated by most of the ( $80 \%)$ golfers. Player 5 described this process of focusing for tournaments as: "I tended to figure this out myself. That this is the best way for me ... we don't discuss what I focus on in tournaments". Player 6 described a similar experience in preparation for tournaments; "We wouldn't discuss beforehand what I focus on. There is no discussion". Player 10 also noted: "My coach and I chat about things, but it is more through experience of what works in the past that I choose to think a certain way. This mindset isn't something that I work on massively”.

Furthermore, the players' view was a shared desire to focus on different areas to that which they focused on during the training session with the coach. A clear preference of players was a focus categorized as "outcome of the skill”. In fact, only Player 2 and $6(20 \%)$ also discussed body components as a target focus, while Player 4 was alone in expressing a preference for holistic "feeling, rhythm, timing" sources of information. Player 3 highlighted the desire to move his thoughts away from what he focused on during a coaching session: The stuff I'm working on just now I wouldn't ever want to be thinking about in a tournament... when I'm in playing mode it would be seeing the flight and reacting to 
the flight. I can't think of a tournament where I've ever played well thinking of body movements.

This same golfer even spoke about the difference between working on technique with his coach to playing in tournaments as feeling like "two different sports". In this vein, another golfer highlighted the difficulty of performing while focusing on body positions: "When I have been thinking technically on what my body is doing, I lose the ability to hit the shot, especially in windy conditions".

Counter to these two experiences, another golfer did say that: "I like to have swing thoughts otherwise I lose a sense of where I want the ball to go"; however then contradicted himself somewhat by reporting similar findings to the previous two quoted golfers: "We [player and coach] are working hard on technical stuff so we don't need to think about it so much in tournaments ... feel the club, focus on where the ball needs to go, see the shot through the air". Other golfers (90\%) also discussed this desire to shift their focus to the feel or outcome of the shot, with Player 4's goal to, "not [be] thinking about where my body should be but how to produce the shot". Player X also spoke of the swing being a "reaction rather than a movement where the body is answering questions that is being asked of it". Notably, several players (40\%) even spoke of a desire to have no thinking while hitting the golf ball. One player said that "I don't like to have thoughts on the golf course at all"; and another stated "I try not to think because the books tell me that's right".

\section{Discussion}

To bring an applied perspective to work on attentional foci in elite level golf, this study addressed the following objectives, to (a) explore the attentional foci promoted or used by elite-level coaches and players when executing different types (i.e., long- and short-game) of golf shots in practice, as well as the rationale for this; and (b) explore the attentional foci 
534

535

536

537

538

539

540

541

542

543

544

545

546

547

548

549

550

551

552

553

554

555

556

557

promoted or used by elite-level coaches and players in competition, as well as the rationale for this. Regarding our first objective, the findings ultimately revealed that:

- various attentional foci were promoted by coaches and used by players in relation to long- and short-game training (i.e., club components/position; body component/position; outcome of the skill; feeling, rhythm, and timing);

- the general type of foci promoted or used in short-game training (i.e., more outcomeand club-related) was different to the general type promoted or used in long-game training (i.e., more body- and club-related);

- coaches had a significant role in shaping the attentional foci of players, yet players often used alternative or additional foci to those promoted by their coach.

From a competition view, our findings revealed that:

- in comparison to training, attentional foci strategies were typically determined by the player rather than by, or with, the coach;

- differences existed between strategies for competition (i.e., mostly outcome-related) and those engaged in long- and short-game training (i.e., more body and club-related).

Finally, across all areas, it was clear that coaches and players used prior experience, rather than specific theory (or practices aligned to specific theory), to inform their approaches.

Overall, our results revealed a complex picture of attentional foci in elite golf that corroborates, contradicts, and challenges different aspects of current fundamental theory; and raises some important considerations for coaches and players. Reflecting our translational aims, we now discuss these main findings in relation to current theory and applied practice. In doing so, we should stress that the design of this study precludes us from inferring whether the patterns and strategies reported by the coaches and players are more or less effective than others. As such, we highlight similarities and differences to previous research only, against 
our aim of promoting a greater applied perspective in attentional focus literature within elite golf.

\section{Foci in Training}

Addressing the long-game, most participants reported using internal foci related to body positions/mechanics, which supports previous research on the preference for internal foci by athletes and coaches (e.g., Carson et al., 2013; Porter et al., 2010), and, therefore, would contradict advice from the constrained action hypothesis research to always employ an external focus of attention (Wulf, 2016) and would not be aligned to the proposed implicit learning strategy by reinvestment theory for those learners with a high propensity for reinvestment (Masters \& Maxwell, 2008). In a few instances, however, participants reported a more complex combination of different foci in the same session; for example, body components, skill outcome, and/or club mechanics. In the view of Collins et al. (2016, p. 1290) "various combinations of external and internal focus . . . will be appropriate, for different tasks, different purposes, with different individuals, [and] at different levels". Accordingly, while all participants were engaged in technical training, differences in the nature and need of foci promoted could have been due to varying session objectives (see Table 1). For instance, some players were clearly in the process of making refinements to their technique whereby an internal focus has been explained as necessary during the early stages as a means of deautomating the targeted kinematics (Carson \& Collins, 2011), while others required clarity or confirmation. Indeed, Carson and Collins (2020) explain that technical training can be administered for reasons beyond technical improvement, such as: increasing confidence ahead of a competition, to "prime" combinations of moves ahead of a specific challenge (e.g., golf course style), reassure a performer when returning from injury, or to raise the social status of a player by demonstrating prowess in front of competitors. As such, the relative emphasis on different process components would seem reasonable because 
583

584

585

586

587

588

589

590

591

592

593

594

595

596

597

598

599

600

601

602

603

604

605

606

607

an understanding of what is required (i.e., how the club should move, desired ball flight) can be achieved much more readily than mastery over how to do it (i.e., executing the technique).

At the very least, the use of multiple foci in a sport with a long coaching history and established body of community knowledge suggests a need to better understand attention as a dynamic process.

Extending this finding, attentional focus in golf might also need to be considered as dynamic across the time course of a single trial. By comparison, expert pistol shooters switch from attending externally on the target to a state of internal intention on the trigger pull during the seconds preceding successful and not unsuccessful shots; as determined by an increase in EEG alpha-power in the occipital cortex (Loze et al., 2001). So, a player might attend to the desired outcome initially (e.g., "this is where I want to hit and the ball flight to get there") and then intend on the process (e.g., "to achieve the outcome I need to swing like. ..”), which reflects an underconsidered methodological approach in current research (see earlier review of, Oliver et al., 2020).

Considering the general use of internal foci for long-game training - and turning to an underexplored area in other golf research (Bernier et al., 2011; Diekfuss \& Raisbeck, 2016) it was notable that this type of foci was not typically transferred to short-game training (at least as reported by coaches and players). Indeed, short-game shots were generally executed with a more outcome (or external) focus. This is a critical distinction, which emphasizes that certain shots under certain contexts may benefit from different types of attentional cues. According to participants, this was due to the variable, but relatively simple nature of shortgame shots; an interpretation that, when combined with our data for long-game shots, is consistent with the theory of meshed control (Christensen et al., 2016), which explains that success on a task is not dependent on a single attentional control style, but is influenced by the task complexity. For simple, well-established skills, fundamental theory shows there to be 
little performance benefit when consciously focussing on body positions since this has disrupted automaticity within these experiments (Beilock \& Carr, 2001; Masters \& Maxwell, 2008; Wulf, 2013). Whereas, mesh control theory would explain that for more complex tasks, the performer can achieve success by utilizing more adaptive or problem solving attentional styles directed towards strategic, situational, and implementation levels. Although, even when a task is simple and highly automated in one context (i.e., stepping at ground level), this is not always facilitated by not thinking when the consequences of failure are very severe (i.e., stepping at height; Collins et al., 2001). In short, these data support our contention that applied studies on attentional focus have the potential to shed deeper (or at least different) and more practically meaningful light than prominent fundamentally-driven studies, especially when considering the goals within both training and competition contexts. Regarding the interaction between coach and player, another notable finding was the extent to which the coach acts as an influential agent in the attentional focus process. While this study showed that players were only partially consistent in applying the cues offered by the coach, there was a clear intention to follow the coaches' instructions. This finding aligns with Diekfuss and Raisbeck (2017), who found that "esteemed individuals", such as coaches, were influential in shaping Division 1 golfers' attentional strategies; a finding also mirrored in high-level tennis (Toner et al., 2020). This suggests, therefore, that technical training needs to be considered as an interactive biopsychosocial process, in that the player's focus (i.e., the psycho) is influenced by the physical skill being performed (i.e., the bio - long-game vs. short-game technique) and who is telling them to focus in a specific way (i.e., the social); not just simply a matter of what a player ultimately focuses on (Carson \& Collins, 2017) that is prioritized by theory from laboratory studies alone.

Reflecting the apparent complexity of this biopsychosocial process, it was notable that players in this study also often replaced, added, or elaborated on the coach's cues. While this 
could be interpreted as an issue of confidence or interest in the coaching provided, a more recent motoric view provided by Carson and Collins (2016) would suggest that this may reflect a more natural search by the player to find greater resonance with their personal representation of the task requirements. In other words, what the players focussed on perhaps made more personal sense in terms of activating the correct movement pattern. On this basis, work has stated the need for collaboration when developing attentional cues, whereby coaches not only address what the performer is doing, but also what the performer thinks they are doing (Carson et al., 2020). In contrast to laboratory-derived theories, these would typically provide a standardized set of instructions to all participants, regardless of their importance or meaning to the participant and their technique (e.g., Wulf \& Su, 2007). Against this backdrop, it is important to understand the rationale for a particular focus being employed before any judgment is passed on its appropriateness. However, coaches and players in this study did not seem "mechanistically aware" when it came to rationalizing their foci. Indeed, most coaches drew on prior experience, either as a player themselves or in their work with a particular player in the past, as attesting to a focus that worked; a finding which could reflect limited knowledge in this area of the game, or a more tacit knowledge-base.

\section{Foci in Competition}

In comparison to the relative influence of the coach in training contexts, and pointing again to the biopsychosocial nature of attention, it was notable that the coach became less influential when the player transitioned to competition; a finding which suggests a potential void in the coaching process (i.e., assisting players in the formation of effective focus strategies for tournament golf). Indeed, while some evidence suggests that there are benefits from adopting external foci during competitive performance (e.g., Halperin et al., 2016), the coaches in this study did not seem to adopt any directive approach for supporting tournament preparation. In this respect, the desire for the golfers to focus externally may be in line with 
findings from Marchant et al. (2007), which showed performers opting for an external focus when given choice of cues. However, it is also in contrast with Porter et al. (2010), in which athletes reported predominantly an internal focus for competition. Either way, there seems to be an absence of coaches working with golfers to appropriately "embed" techniques into skills for competition within the coaching process (Carson \& Collins, 2020).

\section{Limitations, Strengths, and Future Directions}

Although we have contributed to further our understanding of attentional focus in elite golf practice, we recognize certain limitations. Low participant numbers limit the study's generalizability in a traditional sense; although we ask the reader to consider other generalizability's that have been achieved, such as naturalistic generalizability (i.e., the extent to which our findings resonate with the reader's experiences) and analytical generalizability (i.e., the links we have suggested between our findings and established theory; Smith, 2018). As other shortcomings, participant recall may have also been subject to common biases in the interviews and not observing participants in short-game training and competition limited our triangulation of the interview data in these areas. Finally, participants in this study were all male (not as a result of our selection criteria). In a study by Diekfuss and Raisbeck (2016), data suggests that there might be differences in the instructional strategies and application of attentional focus when comparing male versus female sports participants. However, the sample size within this aforementioned study was small (16 males and 15 females), so we propose that this may warrant further investigation using a biopsychosocial lens.

Despite these limitations, the study strengths can be seen in the level of all participants and our attempt to understand a complex process in a naturalistic environment; factors which distinguish this work from prior laboratory studies with less skilled performers. Additionally, methodological coherence has been demonstrated through the consistency of our approaches with our pragmatic philosophy; with a range of methods adopted to enhance 
trustworthiness in the data collection and analysis procedures. Finally, we also ask the reader to apply the "so what?" principle to evaluate the quality of this work.

In this respect, we note that the findings listed at the start of the Discussion point to a practical reality and biopsychosocial complexity in elite golf that much prior work has either overlooked or underconsidered. Indeed, although there still seems to be a significant disconnect between what many scientists advocate and what coaches actually do, this can also be said for what many coaches advocate and what scientists actually research! For example, far more focus has been placed by researchers on what attentional focus strategies can offer to technical execution, without much consideration of how or why technical demands on performers might necessitate differences in attentional focus strategies (e.g., following injury, changes to equipment regulations, or planning for different course conditions). It is, therefore, incumbent on applied scientists to consider if the most important factors relative to practical reality are being studied. At the very least, researchers need to work from why coaches do what they do if they are to facilitate the significant jumps that many would argue are possible. From an applied view, our main findings also challenge golf players, coaches, and coach educators to move beyond a tendency to focus, sometimes exclusively, on technique and consider the extent to which principles from motor control and sport psychology research are accounted for and applied in their practice (cf. Steel et al., 2014; Williams \& Ford, 2009). In this study, it was notable that no player and just one coach stated that their practice was influenced by research on attentional focus; however, they did not expand on exactly how or in what way it was applied. While two other coaches also used the terms "external focus" and "internal focus" in their descriptions, the "what to/when to/how to/where to/why to apply" part of their understanding was not immediately clear. For example, despite a general desire across the coaches to not promote conscious processing, this appeared to be in conflict with reality, where the majority of cues encouraged a focus on 
movement and body parts. Taken with our other findings, this suggests a level of dissonance between what coaches might want and how to achieve it; or more specifically, between the mindset that coaches wish to promote in competition and the one generated on the lesson tee. In summary, it is not clear whether an internal focus of attention was often used because this is more effective in these situations, whether it is because that is the way instructions are typically delivered in golf, or whether researchers and practitioners have not been able to disseminate the attentional focus research findings effectively in this sport.

\section{Concluding Comments}

This practice-focused study with elite level golfers, has revealed that: (a) various attentional foci were used by coaches and players in relation to technical work; (b) different combinations of foci were used across training and competition, and within training itself (i.e., long- versus short-game differences); and (c) players often used alternative or additional foci in training to those promoted by their coaches, or largely self-generated foci in competitive events. While we cannot state that any approaches are more or less effective than others (as our study was explorative rather than evaluative), these results emphasize the biopsychosocial complexity and practical reality that needs to be respected and understood for future research to optimize its value for those operating in the front line of performance. Future work should therefore seek to understand the use of attentional strategies by elite-level players and coaches against these considerations, including their interactions across training and competition as a longitudinal process (e.g., over the course of a season and beyond).

\section{Acknowledgement}

The authors wish to thank Dr XXX XXXXXX for their input and guidance during the early stages of this study's design. 


\section{References}

Bahmani, M., Bahram, A., Diekfuss, J. A., \& Arsham, S. (2019). An expert's mind in action: Assessing attentional focus, workload and performance in a dynamic, naturalistic environment. Journal of Sports Sciences, 37(20), 2318-2330. https://doi.org/10.1080/02640414.2019.1631102

Beilock, S. L., \& Carr, T. H. (2001). On the fragility of skilled performance: What governs choking under pressure? Journal of Experimental Psychology: General, 130(4), 701725. https://doi.org/10.1037/0096-3445.130.4.701

Beilock, S. L., Carr, T. H., MacMahon, C., \& Starkes, J. L. (2002). When paying attention becomes counterproductive: Impact of divided versus skill-focused attention on novice and experienced performance of sensorimotor skills. Journal of Experimental Psychology: Applied, 8(1), 6-16. https://doi.org/10.1037/1076-898x.8.1.6

Bell, J. J., \& Hardy, J. (2009). Effects of attentional focus on skilled performance in golf. Journal of Applied Sport Psychology, 21(2), 163-177. https://doi.org/10.1080/10413200902795323

Bernier, M., Codron, R., Thienot, E., \& Fournier, J. F. (2011). The attentional focus of expert golfers in training and competition: A naturalistic investigation. Journal of Applied Sport Psychology, 23(3), 326-341. https://doi.org/10.1080/10413200.2011.561518

Bobrownicki, R., Collins, D., Sproule, J., \& MacPherson, A. C. (2018). Redressing the balance: Commentary on "Examining motor learning in older adults using analogy instruction”. Psychology of Sport \& Exercise, 38(1), 211-214. https://doi.org/10.1016/j.psychsport.2018.05.014

Bortoli, L., Bertollo, M., Hanin, Y., \& Robazza, C. (2012). Striving for excellence: A multiaction plan intervention model for shooters. Psychology of Sport and Exercise, 13(5), 693-701. https://doi.org/10.1016/j.psychsport.2012.04.006 
Bryant, A. (2009). Grounded theory and pragmatism: The curious case of Anselm Strauss. Biography and Ethnicity, 10(3), Art. 2. https://doi.org/10.17169/fqs-10.3.1358

Carson, H. J., \& Collins, D. (2011). Refining and regaining skills in fixation/diversification stage performers: The Five-A Model. International Review of Sport and Exercise Psychology, 4(2), 146-167. https://doi.org/10.1080/1750984x.2011.613682

Carson, H. J., \& Collins, D. (2016). The fourth dimension: A motoric perspective on the anxiety-performance relationship. International Review of Sport and Exercise Psychology, 9(1), 1-21. https://doi.org/10.1080/1750984X.2015.1072231

Carson, H. J., \& Collins, D. (2017). Refining motor skills in golf: A biopsychosocial perspective. In M. Toms (Ed.), Routledge international handbook of golf science (pp. 196-206). Routledge.

Carson, H. J., \& Collins, D. (2020). Training for success under stress: Appropriately embedding motor skills in sport. In M. Ruiz \& C. Robazza (Eds.), Feelings in sport: Theory, research, and practical implications for performance and well-being (pp. 168-177). Routledge.

Carson, H. J., Collins, D., \& MacNamara, Á. (2013). Systems for technical refinement in experienced performers: The case from expert-level golf. International Journal of Golf Science, 2(1), 65-85. https://doi.org/10.1123/ijgs.2.1.65

Carson, H. J., Robazza, C., Collins, D., Toner, J., \& Bertollo, M. (2020). Optimising performance in sport: An action-based perspective. In M. Bertollo, E. Filho, \& P. Terry (Eds.), Advancements in mental skills training. Routledge.

Chowdhury, M. (2014). Interpretivism in aiding our understanding of the contemporary social world. Open Journal of Philosophy, 4(3), 432-438. https://doi.org/10.4236/ojpp.2014.43047 
Christensen, W., Sutton, J., \& McIlwain, D. (2016). Cognition in skilled action: Meshed control and the varieties of skill experience. Mind and Language, 31(1), 37-66. https://doi.org/10.1111/mila.12094

Christina, R. W. (1987). Motor learning: Future lines of research. In M. J. Safrit \& H. M. Eckert (Eds.), The cutting edge in physical education and exercise science research (pp. 26-41). Human Kinetics.

Collins, D., \& Carson, H. J. (2017). The future for PETTLEP: A modern perspective on an effective and established tool. Current Opinion in Psychology, 16(1), 12-16. https://doi.org/10.1016/j.copsyc.2017.03.007

Collins, D., Carson, H. J., \& Toner, J. (2016). Letter to the editor concerning the article "Performance of gymnastics skill benefits from an external focus of attention" by Abdollahipour, Wulf, Psotta \& Nieto (2015). Journal of Sports Sciences, 34(13), 1288-1292. https://doi.org/10.1080/02640414.2015.1098782

Collins, D., Jones, B., Fairweather, M., Doolan, S., \& Priestley, N. (2001). Examining anxiety associated changes in movement patterns. International Journal of Sport Psychology, 32(3), 223-242.

Collins, L., Carson, H. J., \& Collins, D. (2016). Metacognition and professional judgment and decision making in coaching: Importance, application and evaluation. International Sport Coaching Journal, 3(3), 335-361. https://doi.org/10.1123/iscj.2016-0037

Côté, J., Salmela, J. H., Baria, A., \& Russell, S. J. (1993). Organizing and interpreting unstructured qualitative data. The Sport Psychologist, 7, 127-137.

Culver, D. M., Gilbert, W., \& Sparkes, A. (2012). Qualitative research in sport psychology journals: The next decade 2000-2009 and beyond. The Sport Psychologist, 26(2), 261-281. https://doi.org/10.1123/tsp.26.2.261 
807

808

809

810

811

812

813

814

815

816

817

818

819

820

821

822

823

824

825

826

827

828

829

830

831

Denzin, N., \& Lincoln, Y. (2005). The SAGE handbook of qualitative research. Sage.

Diekfuss, J. A., \& Raisbeck, L. D. (2016). Focus of attention and instructional feedback from NCAA Division 1 collegiate coaches. Journal of Motor Leaning \& Development, 4(2), 262-273. https://doi.org/10.1123/jmld.2015-0026

Diekfuss, J. A., \& Raisbeck, L. D. (2017). Attentional focus in Division 1 golfers. Journal of Motor Learning \& Development, 5(2), 240-251. https://doi.org/10.1123/jmld.2016$\underline{0025}$

Elster, J. (2007). Explaining social behaviour: More nuts and bolts for the social sciences. Cambridge University Press.

Faulkner, G., \& Sparkes, A. (1999). Exercise as therapy for schizophrenia: An ethnographic study. Journal of Sport \& Exercise Psychology, 21(1), 52-69. https://doi.org/10.1123/jsep.21.1.52

Fitts, P. M., \& Posner, M. I. (1967). Human performance. Brooks/Cole Publishing Company.

Giacobbi Jr., P. R., Poczwardowski, A., \& Hager, P. (2005). A pragmatic research philosophy for applied sport psychology. The Sport Psychologist, 19(1), 18-31.

Goldkuhl, G. (2012). Pragmatism vs interpretivism in qualitative information systems research. European Journal of Information Systems, 21(2), 135-146. https://doi.org/10.1057/ejis.2011.54

Gray, R. (2018). Comparing cueing and constraints interventions for increasing launch angle in baseball batting. Sport, Exercise, and Performance Psychology, 7(3), 318-332. https://doi.org/10.1037/spy0000131

Halperin, I., Chapman, D. W., Martin, D. T., Abbiss, C., \& Wulf, G. (2016). Coaching cues in amateur boxing: An analysis of ringside feedback provided between rounds of competition. Psychology of Sport and Exercise, 25, 44-50. https://doi.org/10.1016/j.psychsport.2016.04.003 
832

833

834

835

836

837

838

839

840

841

842

843

844

845

846

847

848

849

850

851

852

853

854

Hanin, Y., Korjus, T., Jouste, P., \& Baxter, P. (2002). Rapid technique correction using old way/new way: Two case studies with Olympic athletes. The Sport Psychologist, 16(1), 79-99.

Jupp, V. (2006). The Sage dictionary of social research methods. Thousand Oaks.

Loze, G. M., Collins, D., \& Holmes, P. S. (2001). Pre-shot EEG alpha-power reactivity during expert air-pistol shooting: A comparison of best and worst shots. Journal of Sports Sciences, 19(9), 727-733. https://doi.org/10.1080/02640410152475856

MacPherson, A. C., Collins, D., \& Morriss, C. (2008). Is what you think what you get? Optimizing mental focus for technical performance. The Sport Psychologist, 22(3), 288-303. https://doi.org/10.1123/tsp.22.3.288

Marchant, C., Clough, P. J., \& Crawshaw, M. (2007). The effects of attentional focusing strategies on novice dart throwing performance and their task experiences. International Journal of Sport \& Exercise Psychology, 5(3), 291-303. https://doi.org/10.1080/1612197X.2007.9671837

Masters, R., \& Maxwell, J. (2008). The theory of reinvestment. International Review of Sport and Exercise Psychology, 1(2), 160-183. https://doi.org/10.1080/17509840802287218

Oliver, A., McCarthy, P. J., \& Burns, L. (2020). Using a “Think Aloud” protocol to understand meta-attention in club-level golfers. International Journal of Sport and Exercise Psychology. https://doi.org/10.1080/1612197X.2020.1766536

Orlikowski, W., \& Baroudi, J. (1991). Studying information technology in organisations: Research approaches and assumptions. Information Systems Research, 2(1), 1-28. https://doi.org/10.1287/isre.2.1.1 
Poolton, J. M., \& Zachry, T. L. (2007). So you want to learn implicitly? Coaching and learning through implicit learning techniques. International Journal of Sports Science and Coaching, 2(1), 67-78. https://doi.org/10.1260/2F174795407780367177

Porter, J. M., Wu, W. F. W., \& Partridge, J. A. (2010). Focus of attention and verbal instructions: Strategies of elite track and field coaches and athletes. Sport Science Review, 19(3-4), 77-89. https://doi.org/10.2478/v10237-011-0018-7

Rendell, M. A., Farrow, D., Masters, R., \& Plummer, N. (2011). Implicit practice for technique adaptation in expert performers. International Journal of Sports Science and Coaching, 6(4), 553-566. https://doi.org/10.1260/1747-9541.6.4.553

Schempp, P., McCullick, B., St Pierre, P., Woorons, S., You, J., \& Clark, B. (2004). Expert golf instructors' student-teacher interaction patterns. Research Quarterly for Exercise and Sport, 75(1), 60-70. https://doi.org/10.1080/02701367.2004.10609134

Singer, R. N. (1986). Sport performance: A five-step mental approach. Journal of Physical Education \& Recreation, 57(4), 82-85. https://doi.org/10.1080/07303084.1986.10606108

Smith, B. (2018). Generalizability in qualitative research: Misunderstandings, opportunities and recommendations for the sport and exercise sciences. Qualitative Research in Sport, Exercise \& Health, 10(1), 137-149. https://doi.org/10.1080/2159676X.2017.1393221

Smith, B., \& McGannon, K. R. (2018). Developing rigor in qualitative research: Problems and opportunities within sport and exercise psychology. International Review of Sport \& Exercise Psychology, 11(1), 101-121. https://doi.org/10.1080/1750984X.2017.1317357 
Sparkes, A. C., \& Smith, B. (2009). Judging the quality of qualitative inquiry: Criteriology and relativism in action. Psychology of Sport and Exercise, 10(5), 491-497. https://doi.org/10.1016/j.psychsport.2009.02.006

Steel, K. A., Harris, B., Baxter, D., King, M., \& Ellam, E. (2014). Coaches, athletes, skill acquisition specialists: A case of misrecognition. International journal of Sports Science \& Coaching, 9(2), 367-378. https://doi.org/10.1260/1747-9541.9.2.367

Strean, W. B. (1998). Possibilities for qualitative research in sport psychology. The Sport Psychologist, 12(3), 333-345. https://doi.org/10.1123/tsp.12.3.333

Toner, J., Carson, H. J., Collins, D., \& Nicholls, A. R. (2020). The prevalence and influence of psychosocial factors on technical refinement amongst highly-skilled tennis players. International Journal of Sport \& Exercise Psychology, 18(2), 201-217. https://doi.org/10.1080/1612197X.2018.1511621

Toner, J., \& Moran, A. (2015). Enhancing performance proficiency at the expert level: Considering the role of 'somaesthetic awareness'. Psychology of Sport and Exercise, 16(Part 1), 110-117. https://doi.org/10.1016/j.psychsport.2014.07.006

Whitley, R. (1984). The scientific status of management research as a practically-oriented social science. Journal of Management Studies, 21(4), 369-390. https://doi.org/10.1111/j.1467-6486.1984.tb00234.x

Williams, A. M., \& Ford, P. R. (2009). Promoting a skills-based agenda in Olympic sports: The role of skill-acquisition specialists. Journal of Sports Sciences, 27(13), 13811392.

Wulf, G. (2013). Attentional focus and motor learning: A review of 15 years. International Review of Sport and Exercise Psychology, 6(1), 77-104. https://doi.org/10.1080/1750984x.2012.723728 
902 Wulf, G. (2016). An external focus of attention is a conditio sine qua non for athletes: A

903 response to Carson, Collins, and Toner (2015). Journal of Sports Sciences, 34(14),

904 1293-1295. https://doi.org/10.1080/02640414.2015.1136746

905 Wulf, G., Höß, M., \& Prinz, W. (1998). Instructions for motor learning: Differential effects of internal versus external focus of attention. Journal of Motor Behavior, 30(2), 169179. https://doi.org/10.1080/00222899809601334

908

Wulf, G., \& Su, J. (2007). An external focus of attention enhances golf shot accuracy in

909 beginners and experts. Research Quarterly for Exercise and Sport, 78(4), 384-389.

910 https://doi.org/10.1080/02701367.2007.10599436 
Table 1. Foci Promoted and Used for Long-Game Shots in Training Session

\begin{tabular}{|c|c|c|c|c|c|c|c|}
\hline $\begin{array}{l}\text { Coach } \\
- \\
\text { Player } \\
\text { Pair } \\
\end{array}$ & $\begin{array}{l}\text { Session } \\
\text { Goal(s) }\end{array}$ & $\begin{array}{c}\text { Nature and Target of Foci } \\
\text { Promoted by the Coach to } \\
\text { Achieve the Session } \\
\text { Goal(s) } \\
\end{array}$ & $\begin{array}{c}\text { Coach } \\
\text { Rationale for } \\
\text { Promoted Foci } \\
\text { (Why) } \\
\end{array}$ & $\begin{array}{l}\text { Consistency of the } \\
\text { Coach's Actions } \\
\text { Within the Session }\end{array}$ & $\begin{array}{c}\text { Nature and target of Player- } \\
\text { Reported Foci Used in the } \\
\text { Session }\end{array}$ & $\begin{array}{c}\text { Player } \\
\text { Rationale } \\
\text { for Foci } \\
\text { Used } \\
\end{array}$ & $\begin{array}{l}\text { Consistency of the } \\
\text { Player's Foci with that } \\
\text { Intended by the Coach }\end{array}$ \\
\hline 1 & $\begin{array}{l}\text { Check set up } \\
\text { tendencies: } \\
\text { Ball flight } \\
\text { control }\end{array}$ & $\begin{array}{l}\text { Club Components / } \\
\text { position: (general club } \\
\text { positions) } \\
\text { Body components / } \\
\text { position: (Set up positions) }\end{array}$ & $\begin{array}{l}\text { Coaching norms } \\
\text { in golf }\end{array}$ & Consistent & $\begin{array}{l}\text { Body components / position: } \\
\text { Left shoulder / left foot / hands } \\
\text { facing down / arm length / trunk } \\
\text { rotation } \\
\text { Outcome of the skill: Start ball } \\
\text { on the correct line }\end{array}$ & $\begin{array}{l}\text { Following } \\
\text { coach } \\
\text { direction }\end{array}$ & Partially consistent \\
\hline 2 & $\begin{array}{l}\text { Wedge play } \\
\text { Club } \\
\text { knowledge. }\end{array}$ & $\begin{array}{l}\text { Club components } \\
\text { /position: (Club face angle) }\end{array}$ & Experience & Consistent & $\begin{array}{l}\text { Club components / position: } \\
\text { Length of swing / Swing } \\
\text { shallower through impact. / face } \\
\text { control } \\
\text { Body components / position: } \\
\text { Rotate body }\end{array}$ & $\begin{array}{l}\text { Following } \\
\text { Coach } \\
\text { direction }\end{array}$ & Partially consistent \\
\hline 3 & $\begin{array}{l}\text { Clarity and } \\
\text { direction on } \\
\text { technical } \\
\text { points. }\end{array}$ & $\begin{array}{l}\text { Body } \\
\text { components/position: } \\
\text { Connection/Set up and } \\
\text { balance. Arms and body } \\
\text { working together } \\
\text { Outcome of the skill: Ball } \\
\text { flight } \\
\text { Feeling, rhythm, timing: } \\
\text { tempo and rhythm }\end{array}$ & $\begin{array}{l}\text { Experience } \\
\text { Peer influence } \\
\text { Constrained } \\
\text { Action } \\
\text { Hypothesis }\end{array}$ & Consistent & $\begin{array}{l}\text { Body Components / Position: } \\
\text { Arm hang /Posture / Balance / } \\
\text { stability / Setting up left, } \\
\text { shoulders too open / connection }\end{array}$ & $\begin{array}{l}\text { Following } \\
\text { coach } \\
\text { directions }\end{array}$ & Partially consistent \\
\hline 4 & $\begin{array}{l}\text { Pitching - } \\
\text { improve face } \\
\text { angle and } \\
\text { launch angle } \\
\text { Full swing- } \\
\text { Not moving } \\
\text { head off the } \\
\text { ball }\end{array}$ & $\begin{array}{l}\text { Body components / } \\
\text { position: Weight more left } \\
\text { side / butt of club rotating } \\
\text { with sternum / quiet legs } \\
\text { Outcome of the skill: Hit } \\
\text { ball over sticks }\end{array}$ & $\begin{array}{l}\text { Peer influence } \\
\text { Experience }\end{array}$ & Consistent & $\begin{array}{l}\text { Body components / position: } \\
\text { Left leg lead out then snap back } \\
\text { through impact / Upper body } \\
\text { rotate on top through impact / } \\
\text { Squarer stance at address / } \\
\text { Improved sequencing }\end{array}$ & $\begin{array}{l}\text { Following } \\
\text { coach } \\
\text { directions }\end{array}$ & Partially consistent \\
\hline 5 & Improve strike & $\begin{array}{l}\text { Body components / } \\
\text { position: Better hand path, } \\
\text { weight shift / Rotating body } \\
\text { through ball better }\end{array}$ & $\begin{array}{l}\text { Peer influence } \\
\text { Experience }\end{array}$ & Consistent & $\begin{array}{l}\text { Club components / position: } \\
\text { Miss the stick } \\
\text { Outcome of the skill: Feeling the } \\
\text { strike }\end{array}$ & $\begin{array}{l}\text { Following } \\
\text { coach } \\
\text { directions }\end{array}$ & Partially consistent \\
\hline
\end{tabular}




\section{Club components /}

position: Club path and

better contact

Neutral ball Body components

flight

Patterns

Improved

movemen

Keeping the swing neutral

position: Address in

tailbone / What happens in

his midsection / Right

arm/shoulder function.

Club components /

position: Awareness on

strike location and its effect

Outcome of the skill: ball

flight focus

Body components

position: Keep arms more

neutral, less behind on

backswing

$\begin{array}{ll}\text { Connection } & \text { Body components / } \\ \text { between club } & \text { position: } £ 10 \text { and headcover }\end{array}$

and body -

flatter plane

note under arm for

connection / Pinch shirt

together

Set up

9

$\begin{array}{ll}\text { Weight shift } & \begin{array}{l}\text { Club components / } \\ \text { position: Pressure in the } \\ \text { right foot longer / Turn }\end{array} \\ \text { Plane } & \text { chest faster than lower bod }\end{array}$

right foot longer / Turn

chest faster than lower body

Body components /

position: Not too bump into

umbrella with hip

More stability
in transition

Body Components /

position: Turn body rather

than hyperextended left arm

/ Something in between his

shoulder blade to keep in

place
Constrained

Action

Hypothesis

Experience

Consistent

Peer influence

Experience

Experience

Consistent

Peer influence

Constrained

Action

Hypothesis

Experience

Consistent

Coaching norms in golf

Theory

Consistent

Peer influence
Body components / position:

Rotation of upper body / Hip to

pole to move weight

Body components / position:

Core engaged / Keep body down

in backswing / Right shoulder

sitting back / Paint wall with hips

Following

coach

directions

Consistent

Club components/position: Toe / Following coach

heel awareness / Keep clubface

square through the ball / transition directions of club

\section{Body components / position:}

Keeping my legs more stable gets

club on plane / Flatten left wrist

Club components / position:

Clubface at address / More from

inside at impact

Body components / position:

Keep shirt tucked on backswing /

Outcome of the skill:

Understanding how to read ball

flight

Body components / position:

Stabilise right side in transition -

Right knee and right foot / Turn

chest through more through

impact / Piece of cardboard under

right foot

Club components / position:

Face stability on way back and

less flippy on way through

Body components / position:

Shoulders back on ribcage / fuller

turn of shoulders / Holding

something between my shoulder

blades.
Following Partially consistent

direction

Following

coach

directions

Partially consistent

Following

coach

directions

(1)




\begin{tabular}{|c|c|c|c|c|c|c|c|c|}
\hline & \multicolumn{4}{|c|}{ Coach Responses } & \multicolumn{4}{|c|}{ Player Responses } \\
\hline $\begin{array}{c}\text { Coach- } \\
\text { Player Pair }\end{array}$ & $\begin{array}{l}\text { Foci promoted for } \\
\text { the same session } \\
\text { goal but with short- } \\
\text { game shots }\end{array}$ & $\begin{array}{l}\text { Rationale for } \\
\text { Foci promoted } \\
\text { with short- } \\
\text { game shots }\end{array}$ & $\begin{array}{l}\text { Foci Promoted in } \\
\text { Competition }\end{array}$ & $\begin{array}{c}\text { Rationale for } \\
\text { Foci } \\
\text { promoted in } \\
\text { Competition }\end{array}$ & $\begin{array}{c}\text { Foci used for the } \\
\text { same session goal } \\
\text { but with short game } \\
\text { shots }\end{array}$ & $\begin{array}{c}\text { Rationale } \\
\text { for Foci } \\
\text { Used for } \\
\text { short-game } \\
\text { shots }\end{array}$ & $\begin{array}{l}\text { Foci Used in } \\
\text { Competition }\end{array}$ & $\begin{array}{c}\text { Rationale for Foci } \\
\text { Used in } \\
\text { Competition }\end{array}$ \\
\hline 1 & $\begin{array}{l}\text { Club components / } \\
\text { position: (Varied } \\
\text { lies / Club angle of } \\
\text { attack / Ball and } \\
\text { strike location) }\end{array}$ & $\begin{array}{l}\text { Philosophy } \\
\text { Experience }\end{array}$ & $\begin{array}{l}\text { An awareness cue } \\
\text { not a body } \\
\text { feeling. }\end{array}$ & Experience & $\begin{array}{l}\text { Club component / } \\
\text { position: Allow the } \\
\text { face to rotate open a } \\
\text { little bit / Less lean } \\
\text { forward in the shaft) }\end{array}$ & $\begin{array}{l}\text { Experience } \\
\text { Following } \\
\text { coach } \\
\text { direction }\end{array}$ & $\begin{array}{l}\text { Outcome of the } \\
\text { skill: Zone in on } \\
\text { target }\end{array}$ & Experience \\
\hline 2 & $\begin{array}{l}\text { Outcome of the } \\
\text { skill: Focus on } \\
\text { where you want the } \\
\text { shot to finish } \\
\text { Body component / } \\
\text { position: Setup / } \\
\text { posture }\end{array}$ & Experience & $\begin{array}{l}\text { Outcome of the } \\
\text { skill: Routine is } \\
\text { important / strike }\end{array}$ & $\begin{array}{l}\text { Experience } \\
\text { Education }\end{array}$ & $\begin{array}{l}\text { Outcome of the } \\
\text { skill: Landing spots } \\
\text { - where I want it to } \\
\text { land / focused on the } \\
\text { outcome }\end{array}$ & Experience & $\begin{array}{l}\text { Outcome of the } \\
\text { skill: Landing spots } \\
\text { / start lines } \\
\text { Body components / } \\
\text { position: Rotation. }\end{array}$ & Experience \\
\hline 3 & $\begin{array}{l}\text { Outcome of the } \\
\text { skill: what the ball is } \\
\text { doing }\end{array}$ & $\begin{array}{l}\text { Experience } \\
\text { Peer influence }\end{array}$ & $\begin{array}{l}\text { Foci preferred by } \\
\text { the player }\end{array}$ & Experience & $\begin{array}{l}\text { Feeling, rhythm, } \\
\text { timing: } \\
\text { Feel, visualise, more } \\
\text { reaction }\end{array}$ & $\begin{array}{l}\text { Coaching } \\
\text { Experience }\end{array}$ & $\begin{array}{l}\text { Outcome of the } \\
\text { skill: What the ball } \\
\text { has to do / seeing } \\
\text { and reacting to the } \\
\text { flight. }\end{array}$ & Experience \\
\hline 4 & $\begin{array}{l}\text { Body components / } \\
\text { position; More set } \\
\text { up related }\end{array}$ & Experience & $\begin{array}{l}\text { Body } \\
\text { components / } \\
\text { position: One set } \\
\text { up thought. } \\
\text { Feeling, Rhythm, } \\
\text { Timing: one } \\
\text { swing feeling }\end{array}$ & Experience & $\begin{array}{l}\text { Body components / } \\
\text { position Lower body } \\
\text { stable }\end{array}$ & Experience & $\begin{array}{l}\text { Feeling, Rhythm, } \\
\text { Timing: I play best } \\
\text { when I have } \\
\text { feelings rather than } \\
\text { thoughts. Turn a } \\
\text { thought into a } \\
\text { feeling. }\end{array}$ & Experience \\
\hline 5 & $\begin{array}{l}\text { Club components / } \\
\text { position: Release } \\
\text { club, club leans } \\
\text { forward a little too }\end{array}$ & $\begin{array}{l}\text { Experience } \\
\text { Constrained } \\
\text { Action }\end{array}$ & $\begin{array}{l}\text { Outcome of the } \\
\text { shot: More about } \\
\text { shots rather than } \\
\text { movements / Shot }\end{array}$ & Experience & $\begin{array}{l}\text { Outcome of the } \\
\text { shot: Ball flight / } \\
\text { Run out / Landing } \\
\text { spot }\end{array}$ & Experience & $\begin{array}{l}\text { Outcome of the } \\
\text { skill Outcome of } \\
\text { shot / How far it } \\
\text { goes / Shot shape }\end{array}$ & $\begin{array}{l}\text { Experience / I } \\
\text { tended to figure this } \\
\text { out myself. }\end{array}$ \\
\hline
\end{tabular}


More club based on Education visualisation on

short game

6

Club components / position how golf

club is delivered,

different lies

7

Outcome of the shot

shot and club for

situation / landing

spot

Club components /
position: more set

up references

Outcome of the

shot: Into the shot

Feeling, Rhythm,

timing: Feeling the shot more
Education

Experience

Peer influence

Experience

Feeling, rhythm, timing: tempo

Outcome of the

shot: target

Education

No specific focus preferred

Experience

Foci preferred by

the player
Outcome of the shot We are

working more on flight of the ball

$\begin{array}{ll}\text { Outcome of the } & \text { Experience } \\ \text { shot: Work on more } & \\ \text { shots rather than } & \text { Philosophy } \\ \text { technique } & \end{array}$

Experience.

Never plays

well with

internal

thoughts

Experience

Education

Theory

Peer influence

Experience

Knows the

player well

\section{Outcome of the \\ shot: See where \\ want to land it /}

\section{Club components}

position: I focus

more on the clubhead

and not the body and

the arms

\section{Outcome of the}

shot: I focus on the

end result

Body components /

position Set up

thoughts a lot

\section{Outcome of the}

shot: engaged in the

shot / picture the shot

Experience

Experience

Education

Peer influence

Theory

Outcome of the

shot:

Flight of the ball /

Landing spot
Experience

Body components /
position: One or

two things - core

and arms come

down before my

hips fire / Posture -

don't get slumped

Outcome of the

shot: Picturing the ball flying off with

a draw or fade.

Experience

Club components / Experience:

position: legs Reduces pressure.

stable, wrist flatter $\quad$ Mind off result

Outcome of the

shot: Target

Experience

Outcome of the

shot: Initial thought

is where I want the

ball to finish
Outcome of the

shot: The shot and Experience 